\title{
Variability of lung function and respiratory muscles power in healthy and asthmatic subjects
}

\begin{abstract}
Airway function is one of the many biologic functions that exhibit circadian variability over 24-h periods. Studies of circadian variability of lung function in normal subjects as well as asthmatics are particularly scarce, and those of MEP and MIP are unknown. The aim of this study to determine circadian variation in lung function (FVC, FEV1 and PEFR) and respiratory muscle pressures(MEP and MIP) for measurement of respiratory muscle power at 6:00am (early morning),12:00midday, 6:00pm( evening) and 12:00 midnight in healthy subjects and in patients with mild asthma at 6:00am and $6: 00 \mathrm{pm}$, to elaborate on the possibility of using MEP and MIP variability as a new diagnostic test for asthma. This is a cross sectional study performed in Khartoum, the capital of Sudan during December 2010. Thirty healthy, symptoms free non smokers normal subjects aged 20-64 years selected randomly and 15 mild asthmatics, clinically free during the time of study aged 19-49 years were included in the study. There is significant drop in healthy subjects early in the morning compared to 6:00pm, the drop in FVC was $9.75 \%$, in FEV1 was $8.79 \%$, in PEFR was $8.44 \%$, in MEP was $10.04 \%$, and in MIP was $17.57 \%$. There is also significant drop in asthmatics early in the morning in MEP and MIP $(21.76 \%, 27.57 \%$ respectively), is comparable to FEV1 $(22.56 \%)$ and PEFR $(23.86 \%)$. The sensitivity and specificity of variability for MEP $(53 \%, 77 \%)$ and MIP $(60 \%, 63 \%)$ comparable to sensitivity and specificity of FEV1 variability $(40 \%, 86 \%)$ and PEFR variability $(46 \%, 73 \%)$. The obtained comparable results of MEP, MIP variability to FEV1, PEFR variability in normal and asthmatic subjects could imply that MEP \& MIP can be used in assessing airway calibre as in asthma. The study concluded that MEP \& MIP variability could be sensitive tests to confirm asthma diagnosis.
\end{abstract}

Keywords: lung function, respiratory muscle power, circadian variability, asthma
Volume 6 Issue $3-2019$

\author{
Omer Abdalla Elbedri Abdalla,' Omer A \\ Musa, ${ }^{2}$ \\ 'Department of Physiology, Elsheikh Abdallah Elbadri University, \\ Sudan \\ ${ }^{2}$ Department of Physiology, National Ribat University, Sudan
}

Correspondence: Omer Abdalla Elbedri Abdalla, Department of Physiology, Faculty of Medicine, Elsheikh Abdallah Elbadri University, Berber, PO Box 25, Nile State, Sudan, Email omerbedril I@gmail.com

Received: July 22, 2019 | Published: August 12, 2019
Abbreviations: FVC, forced vital capacity; FEV1, forced expiratory volume in first second; PEFR, peak expiratory flow rate; MEP, maximal expiratory pressure; MIP, maximal inspiratory pressure

\section{Introduction}

Airway function is one of the many biologic functions that exhibit variability over $24-\mathrm{h}$ periods. This variability has been found to worsen the lung function at night in patients with asthma and to a lesser extent, with chronic obstructive pulmonary disease (COPD). ${ }^{1}$ As nocturnal asthma is common and troublesome, circadian variation in airway function has been of considerable interest in respiratory medicine. ${ }^{1-3}$ It has been recognized that diurnal variation in airway caliber occurs in healthy subjects as well. ${ }^{4}$ In these subjects, a decrease of about $4 \%$ of the average early morning level has been found in FEV1, and of about $8 \%$ of the average level in the peak expiratory flow (PEF). ${ }^{5,6}$ In asthmatics, nocturnal wheezing is associated with a much larger diurnal variability, with a time course identical to that seen in healthy subjects. The change over $24 \mathrm{~h}$ may even be greater than $50 \%$ in asthmatics. ${ }^{7}$ Diurnal variation in pulmonary function has never been investigated in large (longitudinal) studies of the natural history of asthma and COPD. Knowledge about diurnal variation in lung function mainly derived from clinical and occupational studies. ${ }^{4,8}$ The number of subjects involved in such studies of diurnal variation and the number of measurements made within a subject over the day usually are small, whereas the recording of the time of day often lacks detail ("morning, noon, evening, bedtime"). Of the ventilatory function indices, circadian variation in PEF has been studied most often. ${ }^{9}$ Studies of forced expiratory volume in first second (FEV1) and forced vital capacity (FVC) are particularly scarce, ${ }^{4,8}$ and those of MEP and MIP are unknown.

Previous Studies showed that airway resistance is higher at night. Therefore, variables such as specific airway conductance (SCaw), FEV1, FVC and PEFR are lower at night. In asthmatics the phase of changes is identical to normal subjects but the amplitude is much larger. ${ }^{10}$ Studies of variability of spirometric variables in asthmatics are very scarce a part from PEFR and this could be due to difficulty in obtaining frequent measurements throughout the day as it may be somewhat exhausting and bothering for the subjects. PEFR is best used to provide estimate variability of airflow through multiple measurements over the day. Increased variability may be evident from twice daily readings. More frequent readings may result in a better estimate. ${ }^{11}$ PEFR variability is best calculated as the difference between the highest and lowest readings divided by lowest reading and expressed as the percent change. ${ }^{12-14}$ PEFR variability may reach $20 \%$ or more in asthmatic subjects and the values may be less than that in case of twice reading, in such circumstances some use $15 \%$ change in PEFR variability. ${ }^{15}$ Studies of PEFR variability showed sensitivity between 19 and 33\% for identifying diagnosed asthma. ${ }^{16}$ PEFR variability might increase in patients with conditions commonly confused with asthma, so the test is less specific in asthma diagnosis. ${ }^{17,18}$ 
Therefore, there is a need for a better variability method for asthma diagnosis. FEV1 and PEFR are dependent on the respiratory muscle power. So, it is worthy investigating the variability of respiratory muscle power in asthma diagnosis.

\section{Objectives}

\section{General:}

- To study the variability in lung function and respiratory muscles power in healthy and asthmatic adults

\section{Specific:}

- To study the circadian variation in lung function (FVC, FEV1 and PEFR) at 6:00am (early morning), 12:00midday, 6:00pm (evening) and 12:00midnight in healthy subjects.

- To study the diurnal variability in respiratory muscle pressures (MEP and MIP) at 6:00am (early morning), 12:00midday, 6:00pm (evening) and 12:00midnight in healthy subjects.

- To study circadian variation in lung function in patients with mild asthma at 6:00am and 6:00pm.

- To study circadian variation in respiratory muscle pressures in patients with mild asthma at 6:00am and 6:00pm.

- To elaborate on the possibility of using MEP and MIP variability as a new diagnostic test for asthma.

\section{Subjects \& methods}

This is a cross sectional study performed in Khartoum, the capital of Sudan during December 2010. Thirty healthy, symptoms free non smokers normal subjects (17 males and 13 females) aged 20-64 years selected randomly and 15 mild asthmatics, clinically free during the time of study ( 9 males and 6 females) subjects aged 19-49 years were included in the study. Subjects were informed of the procedure and each one provided written consent to participate. Height (ht) and weight (wt) were measured for all subjects using height and weight measuring scales respectively. Lung Function Test (FVC, FEV1, PEFR) and respiratory mouth pressures (MEP, MIP) for measurement of respiratory muscle power, had been done for all subjects by Digital Spiro meter and Respiratory Pressure Meter respectively at 6:00am, 12:00midday, $6: 00 \mathrm{pm}$ and 12:00midnight for normal healthy subjects and at 6:00am and 6:00pm for asthmatic subjects. Paired t test was used to compare results and $\mathrm{P}$ value $\leq 0.05$ considered to be significant

\section{Results}

Mean, standard deviation (SD) of age, ht, wt and BMI for normal healthy subjects were: $32.27 \pm 9.73$ years, $169.17 \pm 7.11 \mathrm{~cm}$, $70.07 \pm 13.05 \mathrm{~kg}$ and $24.58 \pm 3.86$ respectively (Table 1). Mean, SD of age, ht, wt, BMI for asthmatics were: $27.67 \pm 9.44$ years, $170.00 \pm 8.11 \mathrm{~cm}, 68.06 \pm 16.43 \mathrm{~kg}$ and $23.54 \pm 5.30$ respectively (Table 1). There is no statistical difference in age, ht, wt and BMI between healthy subjects and asthmatics as show in (Table 1). Mean, SD of FVC, FEV1, PEFR, MEP and MIP at 6:00am for normal subjects were: $3.03 \pm 0.56 \mathrm{~L}, 2.73 \pm 0.60 \mathrm{~L}, 342.67 \pm 116.38 \mathrm{~L} / \mathrm{sec}, 95.87 \pm 32.65 \mathrm{~cm}$ $\mathrm{H}_{2} \mathrm{O}$ and $78.33 \pm 28.58 \mathrm{~cm} \mathrm{H}_{2} 0$ respectively compared to $3.32 \pm 0.56 \mathrm{~L}$, $2.97 \pm 0.58 \mathrm{~L}, \quad 371.60 \pm 127.48 \mathrm{~L} / \mathrm{sec}, \quad 106.50 \pm 38.61 \mathrm{~cm} \quad \mathrm{H}_{2} 0 \quad$ and $92.13 \pm 32.44 \mathrm{~cm} \mathrm{H}_{2} \mathrm{O}$ respectively at $6: 00 \mathrm{pm}$ (Table 2). There is significant drop in healthy subjects early in the morning compared to 6:00pm, the drop in FVC was 9.75\%, in FEV1 was 8.79\%, in PEFR was $8.44 \%$, in MEP was $10.04 \%$, and in MIP was $17.57 \%$ (Table 2). There is a slight drop between 12:00midnight and 6:00 pm, the \% drop in FVC was $5.70 \%$, in FEV1 was $5.32 \%$, in MIP was $6.55 \%$ (Table 3). Mean, SD of FVC, FEV1, PEFR, MEP, and MIP for asthmatics at $6: 00 \mathrm{am}$ were: $2.99 \pm 0.50 \mathrm{~L}, 2.26 \pm 0.44 \mathrm{~L}, 285.93 \pm 84.66 \mathrm{~L} / \mathrm{sec}$, $66.46 \pm 14.02 \mathrm{~cm} \mathrm{H}_{2} \mathrm{O}$ and $62.60 \pm 13.64 \mathrm{~cm} \mathrm{H}_{2} \mathrm{O}$ respectively compared to $3.40 \pm 0.47 \mathrm{~L}, 2.77 \pm 0.45 \mathrm{~L}, \quad 353.93 \pm 66.92 \mathrm{~L} / \mathrm{sec}, \quad 80.60 \pm 11.13 \mathrm{~cm}$ $\mathrm{H}_{2} \mathrm{O}, 79.86 \pm 8.24 \mathrm{~cm} \mathrm{H}_{2} \mathrm{O}$ respectively at 6:00pm. There is significant drop in asthmatics early in the morning in MEP and MIP $(21.76 \%$, $27.57 \%)$, is comparable to FEV1 (22.56\%) and PEFR $(23.86 \%)$ (Table 4$)$. The sensitivity and specificity of variability for MEP $(53 \%$, $77 \%)$ and MIP $(60 \%, 63 \%)$ comparable to sensitivity and specificity of FEV1 variability $(40 \%, 86 \%)$ and PEFR variability $(46 \%, 73 \%)$ (Table 5).

Table I Demographic data of normal healthy subjects $(n=30)$ and asthmatics $(n=15)$

\begin{tabular}{|c|c|c|}
\hline Anthropometric measure & $\begin{array}{l}\text { Normal Adults } \\
\text { (Mean士SD) }\end{array}$ & $\begin{array}{l}\text { Asthmatics } \\
\text { (Mean士SD) }\end{array}$ \\
\hline Age in years & $32.27 \pm 9.73$ & $27.67 \pm 9.44$ \\
\hline Height in $\mathrm{cm}$ & $169.17 \pm 7.11$ & $170.00 \pm 8.11$ \\
\hline Weight in $\mathrm{kg}$ & $70.07 \pm 13.05$ & $68.06 \pm 16.43$ \\
\hline Body mass index (BMI) & $24.58 \pm 3.86$ & $23.54 \pm 5.30$ \\
\hline
\end{tabular}

Table 2 FVC, FEVI, PEFR, MEP and MIP readings at 6:00pm and 6:00am in healthy subjects $(n=30)$

\begin{tabular}{|c|c|c|c|}
\hline Readings & $\begin{array}{l}\text { At 6:00pm } \\
\text { (Mean士SD) }\end{array}$ & $\begin{array}{l}\text { At 6:00am } \\
\text { (Mean士SD) }\end{array}$ & \% Drop \\
\hline FVC in liter & $3.32 \pm 0.56$ & $3.03 \pm 0.56^{*}$ & 9.75 \\
\hline FEVI in liter & $2.97 \pm 0.58$ & $2.73 \pm 0.60 *$ & 8.79 \\
\hline PEFR in liter/sec & $371.60 \pm 127.48$ & $342.67 \pm 116.38^{*}$ & 8.44 \\
\hline MEP in $\mathrm{cmH}_{2} \mathrm{O}$ & $106.50 \pm 38.6 \mid$ & $95.87 \pm 32.65 *$ & 10.04 \\
\hline MIP in $\mathrm{cmH}_{2} \mathrm{O}$ & $92.13 \pm 32.44$ & $78.33 \pm 28.58 *$ & 17.57 \\
\hline
\end{tabular}

Table 3 FVC, FEVI and MIP at 6:00pm and 12:00 midnight in healthy subjects $(n=30)$

\begin{tabular}{llll}
\hline Readings & $\begin{array}{l}\text { At 6:00pm } \\
\text { (Mean } \pm \text { SD) }\end{array}$ & $\begin{array}{l}\text { At 12:00 midnight } \\
\text { (Mean } \pm \text { SD) }\end{array}$ & \% change \\
\hline FVC in Liter & $3.32 \pm 0.56$ & $3.14 \pm 0.63^{*}$ & 5.70 \\
FEVI in Liter & $2.97 \pm 0.58$ & $2.82 \pm 0.63^{*}$ & 5.32 \\
MIP in $\mathrm{cm} \mathrm{H}_{2} \mathrm{O}$ & $92.13 \pm 32.44$ & $86.47 \pm 30.90^{*}$ & 6.55 \\
\hline
\end{tabular}


Table 4 FVC, FEVI, PEFR, MEP and MIP readings at 6:00pm and 6:00am in asthmatic subjects $(n=15)$

\begin{tabular}{|c|c|c|c|}
\hline Readings & $\begin{array}{l}\text { At 6:00pm } \\
\text { (Mean } \pm S D)\end{array}$ & $\begin{array}{l}\text { At 6:00am } \\
(\text { Mean } \pm S D)\end{array}$ & $\%$ variation \\
\hline FVC in liter & $3.40 \pm 0.47$ & $2.99 \pm 0.50 *$ & $|3.7|$ \\
\hline FEVI in liter & $2.77 \pm 0.45$ & $2.26 \pm 0.44 *$ & 22.56 \\
\hline PEFR in liter/sec & $353.93 \pm 66.92$ & $285.93 \pm 84.66 *$ & 23.86 \\
\hline MEP in $\mathrm{cm} \mathrm{H} \mathrm{H}_{2} \mathrm{O}$ & $80.60 \pm 11.13$ & $66.46 \pm 14.02 *$ & 21.76 \\
\hline MIP in $\mathrm{cm} \mathrm{H} \mathrm{H}_{2} \mathrm{O}$ & $79.86 \pm 8.24$ & $62.60 \pm 13.64 *$ & 27.57 \\
\hline
\end{tabular}

Table $\mathbf{5}$ The sensitivity and specificity of FEVI, PEFR, MEP and MIP variability

\begin{tabular}{lll}
\hline Variability & Sensitivity & Specificity \\
\hline FEV 1 & $40 \%$ & $86 \%$ \\
PEFR & $46 \%$ & $73 \%$ \\
MEP & $53 \%$ & $77 \%$ \\
MIP & $60 \%$ & $63 \%$ \\
\hline
\end{tabular}

\section{Discussion}

Asthma diagnosis largely depends on symptoms and signs validated by pulmonary function test. ${ }^{19}$ The variability test for asthma diagnosis is performed by comparing PEFR and FEV1 at 6:00am and 6:00pm. ${ }^{11}$ It is known that there is a circadian rhythm in the bronchial tone with maximal bronchoconstriction early in the morning and maximal dilatation in the evening. ${ }^{20}$ The values of PEFR and FEV1 drops by $8.44 \%$ and $8.79 \%$ respectively in normal subjects. Depending on this fact, and with consistent observation that asthma worsen early in the morning, the variability in asthmatic has been used as a confirmative test. A drop of PEFR in asthmatics by $20 \%$ confirm the suspected diagnosis. ${ }^{15}$ This test has been found to have sensitivity between 19 to $33 \%$ with low specificity. PEFR variability might increase in patients with conditions commonly confused with asthma, for this reason the test is less specific in asthma diagnosis. ${ }^{17,18}$ Can we get better values by using MEP and MIP, was the question studied in this section. In fact the results showed that there is significant reduction in MEP (10.04\%) in normal subjects which dropped further to $21.76 \%$ in asthmatics. This is comparable to PEFR variation from $8.44 \%$ in normal subjects to $23.86 \%$ in asthmatics and FEV1 variation from $8.79 \%$ in healthy to $22.56 \%$ in asthmatics (Tables 2, 4). On the other hand, the variability of MIP was high in both normal healthy subjects $(17.57 \%)$ and in asthmatics (27.57\%) compared to other parameters and this could be explained partly by the fact that most of the work load during increased airway resistance is taken over by inspiratory muscles whereas the expiratory muscles recruitment is relatively minor. $^{21}$

Circadian variations in Spiro metric variables (FVC; FEV1; PEFR; TLC, total lung capacity; VC, vital capacity; RV, residual volume) were studied between 9:00am, 9:00pm in 876 adults. FVC, FEV1, PEFR and VC were found to increase from 9:00am until noon and decreased afterwards. TLC was constant over the day while RV decreased from 9:00am to noon. Average variation in FVC, FEV1 and PEFR was $4.8 \%, 2.8 \%$ and $3.1 \%$ respectively. The obtained results were found to be compatible with circadian changes in airway size. ${ }^{22}$
In this study the sensitivity and specificity of MEP was $53 \%, 77 \%$ respectively, and that of MIP was $60 \%, 63 \%$ respectively compared to sensitivity and specificity of FEV1 variability $(40 \%, 86 \%)$ and PEFR variability $(46 \%, 73 \%)$. The higher sensitivity of MEP\& MIP variability compared to FEV1\& PEFR variability may imply that MEP and MIP variability could be a potential diagnostic test for asthma and this needs further elaboration.

PEFR variability was assessed to screen for asthma related conditions in a study conducted by Nino, et al. ${ }^{23}$ PEFR measured twice daily in the morning and evening for 3 weeks. Readings were taken in 5 subgroups (physician diagnosed asthma, current asthma, history of wheezing without colds, hyperreactive detected by positive broncho provocation test and non symptomatic) and in the total study group. In the total study group sensitivity of PEFR variability was $36 \%$ ( PEFR variability $\geq 20 \%$ ) with specificity of $90 \%$. Results were better among subjects with a history of wheezing without colds (sensitivity was $40.0 \%$ with specificity $83.6 \%$ ). The study concluded that PEFR variability might be of great use as a marker of variability in airway calibre in both epidemiological and clinical studies. However, their use in population screening for asthma related conditions has serious limitations because of the large overlap of PEFR variability distribution between asthmatic and non asthmatic individuals and the low sensitivity of PEFR variability even in those with an increased pre test probability of asthma related conditions..$^{23}$

\section{Conclusion}

The obtained comparable results of MEP, MIP variability to FEV1, PEFR variability in normal and asthmatic subjects could imply that respiratory pressure meter (RPM) can be used in assessing airway calibre as in asthma. MEP \& MIP variability could be a sensitive test to confirm asthma diagnosis.

\section{Funding}

My research project was partially or fully sponsored by (Elsheikh Abdallah Elbadri University) with grant number $(1,000 \$)$. In case of no financial assistance for the research work, provide the information regarding the sponsor.

\section{Acknowledgement}

Sincere appreciation to the study group and all workers at Elsheikh Abdallah Elbadri and National Ribat Universities

\section{Conflict of Interest}

Respiratory Physiology Research.

\section{References}

1. Turner-Warwick M. The definition and recognition of nocturnal asthma (with discussion). In: PJ Banes, J Levy, editors. Nocturnal Asthma. Oxford University Press: Oxford; 1984;3-9.

2. Turner-Warwick M. The management of chronic asthma. In: PJ Barnes, IW Rodger, NC Thomson, editors, Asthma: Basic Mechanisms and Clinical Management. London, Academic Press Limited; 1988:721732.

3. Storms WW, S F Bodman, RANathan, et al. Nocturnal asthma symptoms may be more prevalent than we think. J Asthma. 1994;31:313-318. 
4. Cinkotai FF, TC Sharpe, ACC Gibbs. Circadian rhythms in peak expiratory flow rate in workers exposed to cotton dust. Thorax. 1984;39:759-765.

5. Guberan E, M K Williams, J Walford. Circadian variation of F.E.V. in shift workers. Br J Ind Med. 1969;26:121-125.

6. Hetzel MR, TJH Clark. Comparison of normal and asthmatic circadian rhythms in peak expiratory flow rate. Thorax. 1980;35(10):732-738.

7. Hetzel M R. The pulmonary clock Editorial. Thorax. 1981;36:481-486

8. Barnes PJ. Circadian rhythms in the respiratory system. In: J Arendt DS Minors, JM Waterhouse, editors, Biological Rhythms in Clinical Practice. London, Wright; 1989:71-82.

9. Quackenboss JJ, M D Lebowitz, M Krzyzanowski. The normal range of diurnal changes in peak expiratory flow rates. Am Rev Respir. Dis 1991;143:323-330

10. Moore-Edc MC, Czcisler CA, Richardson GS. Circadian time keeping in health and disease. $N$ Engel J Med. 1983;39:469-476.

11. D“Alonzo GE, Steinijans VW, Keller A. Measurements of morning and evening airflow grossly underestimate the circadian variability of FEV1 and peak expiratory flow rate in asthma. Am J Respir Crit Care. Med 1995;152(3):1097-1099.

12. Higgins BG, Britton JR, Chinn S, et al. The distribution of peak flow variability in a population sample. Am Rev Respir Dis. 1989;140(5):1368-1372.

13. Higgins BG, Britton JR, Chinn S, et al. Comparison of bronchia reactivity and peak expiratory flow variability measurements for epidemiologic studies. Am Rev Respir Dis. 1992;145(3):588-593.

14. Quackenboss JJ, Lebowitz MD, Krzyzanowski M. The normal range of diurnal changes in peak expiratory flow rates. Relationship to symptoms and respiratory disease. Am Rev Respir Dis. 1991;143(2):323-330.
15. Boezen HM, Schouten JP, Postma DS, et al. Distribution of peak expiratory flow variability by age, gender and smoking habits in a random population sample aged 20-70 yrs. Eur Respir J. 1994;7(10):1814-1820.

16. Siersted HC, Hansen HS, Hansen NC, et al. Evaluation of peak expiratory flow variability in an adolescent population sample. The Odense Schoolchild Study. Am J Respir Crit Care Med. 1994;149(3):598-603.

17. Hunter CJ, Brightling CE, Woltmann G, et al. A comparison of the validity of different diagnostic tests in adults with asthma. Chest. 2002;121(4):1051-1057.

18. Brand PL, Postma DS, Kerstjens HA, et al. Relationship of airway hyperresponsiveness to respiratory symptoms and diurnal peak flow variation in patients with obstructive lung disease. Am Rev Respir Dis. 1991;143(5-1):916-921.

19. Magzoub AA. Validation of ISSAC questionnaire for asthma diagnosis by pulmonary function test and skin prick tests in Sudanese adults ( Thesis submitted for PhD requirement in Human Physiology). National Ribat University. 2011

20. William F Ganong. Review of medical physiology. 20th ed. Lange Medical Publiction. 2001.

21. Hill AR. Respiratory muscle function in asthma. J Assoc Acad Minor Phys. 1991;2(3):100-108

22. Gerard JM, Wilfrid PH, Beng GV, et al. Diurnal variation in lung function in subgroups from two Dutch populations Consequences for Longitudinal Analysis. Am J Respir Crit Care. 1999;159(4):1163-1171.

23. Nino K, Elisabeth ZS, Andre P, et al. Peak flow variability in the SAPALDIA study and its validity in screening for asthma related conditions. American Journal of Respir and Crit Care Med. $1999 ; 160(2): 428-432$. 